\title{
Keanekaragaman dan Perbedaan Jenis Kupu-kupu (Ordo Lepidoptera) Berdasarkan Topografi pada Tiga Lokasi Hutan di Sulawesi Utara Diversity and Differences type of Butterfly species (Order Lepidoptera) based on the topography of the three forest location in North Sulawesi.
}

\author{
Lidyana Maya Gosa(1)*, Ventje Memah'1), Jimmy Rimbing ${ }^{1)}$ \\ 1)Program Studi Entomologi Pascasarjana Universitas Sam Ratulangi Manado \\ *Email korespondensi: lidya gosal@yahoo.com
}

Diterima 1 Agustus 2016, diterima untuk dipublikasikan 25 Agustus 2016

\begin{abstract}
Abstrak
Kupu-kupu merupakan salah satu bagian dari ekosistem yang fungsinya mempertahankan keseimbangan ekosistem dan memperkaya keanekaragaman hayati. Tujuan penelitian yaitu untuk menganalisis kekayaan, kelimpahan, keanekaragaman dan kemerataan spesies di hutan Danowudu, Masarang dan Kawatak, juga membandingkan jenis kupu-kupu berdasarkan topografi pada ketiga lokasi hutan tersebut. Penelitian ini dilaksanakan di hutan Danowudu, Masarang dan Kawatak dan dilanjutkan di laboratorium dari bulan Maret-Juli 2016. Penelitian ini menggunakan metode transek dan rute dibuat sepanjang $1000 \mathrm{~m}$ untuk setiap transek. Hasil penelitian menunjukkan bahwa kelimpahan, kekayaan dan keanekaragaman spesies kupu-kupu tertinggi di hutan Danowudu. Kemerataan spesies tertinggi di hutan Masarang. Spesies kupu-kupu yang hanya dapat ditemukan di hutan Danowudu (200-240 mdpl) terdiri dari 13 spesies. Spesies kupu-kupu yang hanya dapat ditemukan di hutan kawatak (827-938 mdpl) terdiri dari 7 spesies. Spesies kupu-kupu yang hanya dapat ditemukan di hutan Masarang (1084-1194 mdpl) terdiri dari 3 spesies.

Kata kunci: keanekaragaman, kupu-kupu, Lepidoptera, Sulawesi Utara
\end{abstract}

\begin{abstract}
Butterfly is part of an ecosystem and has function to maintain ecosystem stability and enrich biodiversity. This research aimed to analyze the richness, abundance, diversity and evenness of species in Danowudu, Masarang and Kawatak forest as well as to compare the species of butterflies based on the topography of the three locations of the forest. This research was conducted in Danowudu, Masarang and Kawatak forest and the continued in the laboratory from March to July 2016. This study used a transect method and the route was made as long as $1000 \mathrm{~m}$ for each transect. The results showed that the highest abundance, richness and diversity of butterfly species were in Danowudu forest. The highest evenness of species was in the Masarang forest. Butterfly species that was only found in Danowudu forest (200-240 masl) consisted of 13 species. Butterfly species that was only found in Kawatak forest (827938 masl) included 7 species. Butterfly species that was only found in Masarang forest (1084-1194 masl) comprised 3 species.

Keywords: butterfly, diversity, Lepidoptera, North Sulawesi
\end{abstract}




\section{PENDAHULUAN}

Kupu-kupu merupakan salah satu jenis serangga yang paling banyak diketahui karena terdapat dimana-mana dengan bentuk dan warna yang menarik. Serangga ini dapat dengan mudah dibedakan dengan serangga lain dilihat dari bagian tubuh yang ditutupi oleh sisik (scales) (Sembel 2012).

Kupu-kupu adalah bagian dari ekosistem yang fungsinya mempertahankan keseimbangan ekosistem dan memperkaya keanekaragaman hayati, dilihat dari perannya sebagai penyerbuk yang memungkinkan terjadinya regenerasi tumbuhan. Selain itu juga, kupu-kupu peka terhadap perubahan lingkungan, baik itu dari segi vegetasi maupun dari tingkat pencemaran yang terjadi di lingkungan. Secara ekologis, kupukupu dapat dijadikan bioindikator kesehatan suatu lingkungan. Populasi kupu-kupu yang banyak pada suatu tempat mencerminkan lingkungan tersebut masih baik (Shalihah et al. 2012).

Hutan merupakan habitat dari kupu-kupu, karena merupakan tempat untuk berlindung dan juga tempat mencari makanan baik untuk serangga muda maupun serangga dewasa (Bodang 2002). Kupu-kupu seperti satwa lainnya yang menghadapi ancaman kepunahan dan kelangkaan, yang terutama disebabkan oleh alih fungsi hutan juga habitatnya. Sebagian jenis kupu-kupu sangat tergantung pada satu atau dua jenis tumbuhan yang merupakan tumbuhan inangnya (Peggie 2008). Penebangan hutan dan penangkapan kupu-kupu secara liar dapat mengakibatkan punahnya salah satu spesies, terutama spesies yang dilindungi atau langka (Bodang 2002).

Penelitian tentang spesies kupukupu di Sulawesi cukup banyak dilakukan, antara lain penelitian yang dilakukan oleh Koneri dan Saroyo (2012) di gunung Manado tua, kawasan taman nasional laut Bunaken yang menemukan 4 famili kupu-kupu yaitu dari famili Nymphalidae, Papilionidae, Pieridae dan Satyridae. Di pulau mantehage oleh Lamatoa et al. (2013) yang menemukan 4 famili kupu-kupu yang terdiri dari 19 spesies dengan kelimpahan spesies yaitu dari famili Nymphalidae.

Penelitian keanekaragaman kupu-kupu di hutan Danowudu, Masarang dan Kawatak belum pernah diteliti dan dilaporkan. Padahal, penelitian ini sangat penting karena melihat adanya ahli fungsi lahan dan penebangan pohon pada beberapa kawasan hutan tersebut yang dapat berdampak pada penurunan jenis kupu-kupu terutama kupu-kupu yang langka dan dilindungi. Penelitian ini bertujuan untuk Menganalisis kekayaan, kelimpahan, keanekaragaman, dan kemerataan spesies kupukupu di hutan Danowudu, Masarang dan Kawatak, Sulawesi Utara juga membandingkan jenis kupu-kupu

44 JURNAL BIOSLOGOS, AGUSTUS 2016, VOL. 6 NC

\section{METODOLOGI PENELITIAN}

Penelitian ini dilaksanakan di Kawasan Hutan Danowudu, Masarang dan Kawatak pada Bulan Maret - Juli 2016. Alat dan bahan yang digunakan dalam penelitian yaitu alkohol $70 \%$, peta, GPS (Global Positioning System), altimeter, termometer, higrometer, jaring (sweep net), kertas minyak, styrofoam, kotak koleksi, jarum pentul, jarum suntik, buku identifikasi, kamera dan alat tulis menulis. Penelitian ini menggunakan metode transek. Rute yang dibuat sepanjang $1000 \mathrm{~m}$ untuk setiap transek. Pengaturan stasiun 
pengambilan sampel dilakukan secara purposive random sampling. Prosedur penelitian yang digunakan meliputi pengambilan sampel dan pengukuran faktor lingkungan, identifikasi sampel dengan menggunakan buku kunci identifikasi dan pembuatan spesimen kering.

Analisis data yang dibahas yaitu meliputi kelimpahan (N), kekayaan spesies (S) indeks keanekaragaman spesies $\left(H^{\prime}\right)$, dan indeks kemerataan spesies (E).

Mengukur Keanekaragaman spesies menggunakan Indeks keanekaragaman spesies ShannonWiener (Syahputra 2015) sebagai berikut:

$$
\mathrm{H}^{\prime}=-\sum p_{i} \ln p_{i}
$$

Keterangan :

$p_{i}=n_{i} / N$ (rasio jumlah individu suatu jenis terhadap keseluruhan jenis)

$\mathrm{n}_{\mathrm{i}}=$ Jumlah individu spesies ke-i

$\mathrm{N}=$ Total individu

Mengukur kemerataan jenis dalam setiap komunitas digunakan Indeks Kemerataan Evenness (Odum 1996), dengan rumus:

Keterangan:

$$
E=H^{\prime} / l n S
$$

$\mathrm{E}$ = indeks kemerataan

$H^{\prime}=$ keanekaragaman jenis serangga

Ln = logaritma natural

$S=$ jumlah jenis

\section{HASIL DAN PEMBAHASAN}

Kupu-kupu yang ditemukan pada tiga lokasi penelitian yaitu sebanyak 56 spesies dengan 1285 individu, yang terdiri dari famili nymphalidae, papilionidae, pieridae, lycaenidae dan hesperiidae. Famili nymphalidae merupakan famili yang paling banyak diperoleh yaitu 767 individu (60\%), pieridae sebanyak 316 individu (25\%), papilionidae sebanyak 155 individu (12 $\%$ ), lycaenidae berjumlah 32 individu (2 $\%$ ) sedangkan yang paling sedikit diperoleh dari famili hesperiidae yaitu 15 individu (1 \%) (Gambar 1). Famili nymphalidae ditemukan melimpah dikarenakan pada ketiga lokasi penelitian ini tersedia sumber pakan larva maupun imago dari famili ini.

Famili nymphalidae sering ditemukan melimpah pada berbagai lokasi penelitian seperti penelitian yang dilakukan oleh Lestari et al. (2015) di Wana Wisata Alas Bromo, Priyono dan Abdullah (2013) di Taman Kehati Unnes, Rahayu dan Basukriadi (2012) di Hutan Kota Muhammad Sabki dan Febrita et al. (2014) di Kawasan Wisata Hapanasan Rokan Hulu. Hal ini dikarenakan, famili ini bersifat polifag yaitu memakan banyak spesies tumbuhan dari berbagai famili dan bersifat kosmopolit yang artinya memiliki distribusi tersebar di berbagai wilayah di dunia (Chahyadi dan Bibas 2016; Lestari et al. 2015).

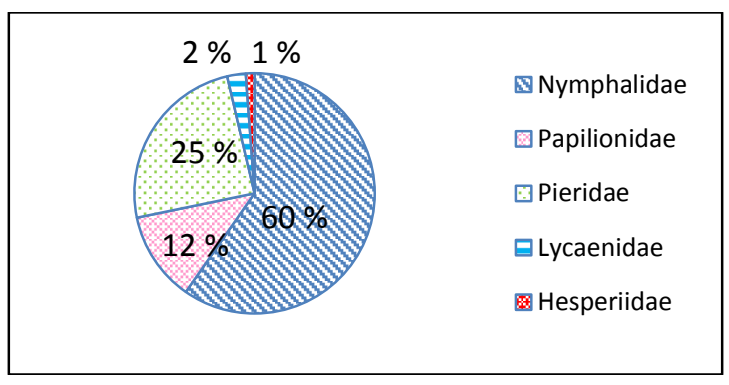

Gambar 1. Famili kupu-kupu yang ditemukan pada tiga lokasi penelitian. 
Tabel 1. Jumlah familia dan spesies kupu-kupu yang ditemukan aı nutan Uanowuau, Kawatak dan Masarang.

\begin{tabular}{|c|c|c|c|c|c|c|c|c|c|}
\hline \multirow[b]{2}{*}{ No } & \multirow[b]{2}{*}{ Famili/Spesies } & \multicolumn{2}{|c|}{ Danowudu } & \multicolumn{2}{|c|}{ Kawatak } & \multicolumn{2}{|c|}{ Masarang } & \multicolumn{2}{|c|}{ Total } \\
\hline & & $\mathrm{Jml}$ & $\%$ & Jml & $\%$ & Jml & $\%$ & Jml & $\%$ \\
\hline I & Nymphalidae & & & & & & & & \\
\hline 1 & Athyma libnites libnites & 0 & 0.00 & 7 & 0.54 & 2 & 0.16 & 9 & 0.70 \\
\hline 2 & Amathusia phidippus celebensis & 3 & 0.23 & 0 & 0.00 & 0 & 0.00 & 3 & 0.23 \\
\hline 3 & Cethosia myrina & 0 & 0.00 & 0 & 0.00 & 2 & 0.16 & 2 & 0.16 \\
\hline 4 & Cyrestis cocles & 6 & 0.47 & 0 & 0.00 & 0 & 0.00 & 6 & 0.47 \\
\hline 5 & Cyrestis strigata & 4 & 0.31 & 8 & 0.62 & 5 & 0.39 & 17 & 1.32 \\
\hline 6 & Danaus genutia leucoglene & 0 & 0.00 & 11 & 0.86 & 0 & 0.00 & 11 & 0.86 \\
\hline 7 & Danaus ismare & 7 & 0.54 & 14 & 1.09 & 0 & 0.00 & 21 & 1.63 \\
\hline 8 & Doleschallia polibete celebensis & 0 & 0.00 & 2 & 0.16 & 0 & 0.00 & 2 & 0.16 \\
\hline 9 & Dophla evelina dermoides & 1 & 0.08 & 0 & 0.00 & 0 & 0.00 & 1 & 0.08 \\
\hline 10 & Elymnias cumaea & 2 & 0.16 & 0 & 0.00 & 0 & 0.00 & 2 & 0.16 \\
\hline 11 & Euploea algae & 9 & 0.70 & 10 & 0.78 & 0 & 0.00 & 19 & 1.48 \\
\hline 12 & Euploea eupator & 0 & 0.00 & 2 & 0.16 & 0 & 0.00 & 2 & 0.16 \\
\hline 13 & Euploea hewitsonii & 10 & 0.78 & 2 & 0.16 & 0 & 0.00 & 12 & 0.93 \\
\hline 14 & Euploea leucostictos westwoodi & 7 & 0.54 & 0 & 0.00 & 16 & 1.25 & 23 & 1.79 \\
\hline 15 & Euthalia amanda & 2 & 0.16 & 0 & 0.00 & 0 & 0.00 & 2 & 0.16 \\
\hline 16 & Faunis menado & 0 & 0.00 & 0 & 0.00 & 9 & 0.70 & 9 & 0.70 \\
\hline 17 & Hypolimnas bolina & 1 & 0.08 & 1 & 0.08 & 0 & 0.00 & 2 & 0.16 \\
\hline 18 & Hypolimnas salmacis & 0 & 0.00 & 0 & 0.00 & 17 & 1.32 & 17 & 1.32 \\
\hline 19 & Idea blanchardii & 11 & 0.86 & 36 & 2.80 & 18 & 1.40 & 65 & 5.06 \\
\hline 20 & Ideopsis vitrea vitrea & 24 & 1.87 & 27 & 2.10 & 11 & 0.86 & 62 & 4.82 \\
\hline 21 & Junonia hedonia & 3 & 0.23 & 152 & 11.83 & 1 & 0.08 & 156 & 12.14 \\
\hline 22 & Lassipa neriphus & 4 & 0.31 & 0 & 0.00 & 0 & 0.00 & 4 & 0.31 \\
\hline 23 & Lohora ophthalmica & 0 & 0.00 & 0 & 0.00 & 3 & 0.23 & 3 & 0.23 \\
\hline 24 & Melanitis leda & 1 & 0.08 & 0 & 0.00 & 4 & 0.31 & 5 & 0.39 \\
\hline 25 & Melanitis phedima & 1 & 0.08 & 0 & 0.00 & 12 & 0.93 & 13 & 1.01 \\
\hline 26 & Melanitis pyrrha & 91 & 7.08 & 21 & 1.63 & 7 & 0.54 & 119 & 9.26 \\
\hline 27 & Mycalesis itys & 0 & 0.00 & 10 & 0.78 & 2 & 0.16 & 12 & 0.93 \\
\hline 28 & Orsotriaena jopas jopas & 1 & 0.08 & 0 & 0.00 & 1 & 0.08 & 2 & 0.16 \\
\hline 29 & Parantica cleona luciplena & 6 & 0.47 & 8 & 0.62 & 12 & 0.93 & 26 & 2.02 \\
\hline 30 & Parasarpa lymire & 4 & 0.31 & 0 & 0.00 & 0 & 0.00 & 4 & 0.31 \\
\hline 31 & Parthenos sylvia salentia & 76 & 5.91 & 3 & 0.23 & 0 & 0.00 & 79 & 6.15 \\
\hline 32 & Tacola eulimene hegelochus & 8 & 0.62 & 0 & 0.00 & 0 & 0.00 & 8 & 0.62 \\
\hline 33 & Tirumala ishmoides ishmoides & 4 & 0.31 & 3 & 0.23 & 0 & 0.00 & 7 & 0.54 \\
\hline 34 & Vindula dejone celebensis & 0 & 0.00 & 3 & 0.23 & 0 & 0.00 & 3 & 0.23 \\
\hline 35 & Ypthima kalelonda & 0 & 0.00 & 25 & 1.95 & 14 & 1.09 & 39 & 3.04 \\
\hline II & Papilionidae & & & & & & & & \\
\hline 36 & Graphium agamemnon & 4 & 0.31 & 2 & 0.16 & 4 & 0.31 & 10 & 0.78 \\
\hline 37 & Graphium milon & 0 & 0.00 & 0 & 0.00 & 11 & 0.86 & 11 & 0.86 \\
\hline 38 & Pachliopta polyphontes polyphontes & 37 & 2.88 & 0 & 0.00 & 3 & 0.23 & 40 & 3.11 \\
\hline 39 & Papilio ascalaphus & 4 & 0.31 & 1 & 0.08 & 0 & 0.00 & 5 & 0.39 \\
\hline 40 & Papilio blumei & 0 & 0.00 & 12 & 0.93 & 0 & 0.00 & 12 & 0.93 \\
\hline 41 & Papilio gigon & 22 & 1.71 & 8 & 0.62 & 3 & 0.23 & 33 & 2.57 \\
\hline 42 & Papilio sataspes & 8 & 0.62 & 5 & 0.39 & 5 & 0.39 & 18 & 1.40 \\
\hline 43 & Troides helena & 26 & 2.02 & 0 & 0.00 & 0 & 0.00 & 26 & 2.02 \\
\hline III & Pieridae & & & & & & & & \\
\hline 44 & Catopsilia scylla asema & 0 & 0.00 & 15 & 1.17 & 33 & 2.57 & 48 & 3.74 \\
\hline 45 & Cepora timnatha & 1 & 0.08 & 0 & 0.00 & 0 & 0.00 & 1 & 0.08 \\
\hline 46 & Delias rosenbergi & 0 & 0.00 & 6 & 0.47 & 0 & 0.00 & 6 & 0.47 \\
\hline 47 & Delias zebuda & 0 & 0.00 & 7 & 0.54 & 49 & 3.81 & 56 & 4.36 \\
\hline 48 & Elodina sota & 4 & 0.31 & 0 & 0.00 & 0 & 0.00 & 4 & 0.31 \\
\hline 49 & Eurema tominia & 19 & 1.48 & 66 & 5.14 & 38 & 2.96 & 123 & 9.57 \\
\hline 50 & Hebomoia glaucippe celebensis & 16 & 1.25 & 0 & 0.00 & 0 & 0.00 & 16 & 1.25 \\
\hline 51 & Pareronia tritaea & 62 & 4.82 & 0 & 0.00 & 0 & 0.00 & 62 & 4.82 \\
\hline IV & Lycaenidae & & & & & & & & \\
\hline 52 & Nacaduba hermus & 0 & 0.00 & 14 & 1.09 & 0 & 0.00 & 14 & 1.09 \\
\hline 53 & Pithecops phoenix & 1 & 0.08 & 0 & 0.00 & 17 & 1.32 & 18 & 1.40 \\
\hline
\end{tabular}

lanjutan......... 
JURNAL BIOSLOGOS, AGUSTUS 2016, VOL. 6 NOMOR 2

\begin{tabular}{cccccccccc}
\hline & & \multicolumn{3}{c}{ Danowudu } & \multicolumn{2}{c}{ Kawatak } & \multicolumn{2}{c}{ Masarang } & \multicolumn{2}{c}{ Total } \\
\cline { 3 - 9 } No & \multicolumn{1}{c}{ Famili/Spesies } & Jml & $\%$ & Jml & $\%$ & Jml & $\%$ & Jml & $\%$ \\
\hline V & Hesperiidae & 0 & 0.00 & 3 & 0.23 & 0 & 0.00 & 3 & 0.23 \\
54 & Notocrypta clavata & 0 & 0.00 & 1 & 0.08 & 2 & 0.16 & 3 & 0.23 \\
55 & Prusiana kuehni & 7 & 0.54 & 2 & 0.16 & 0 & 0.00 & 9 & 0.70 \\
56 & Tagiades trebellius trebellius & 497 & 38.68 & 487 & 37.90 & 301 & 23.42 & 1285 & 100.00 \\
N & & 498 &
\end{tabular}

Spesies kupu-kupu yang umumnya terdapat pada ketiga lokasi penelitian adalah Junonia hedonia (12.14\%) berjumlah 156 individu yang paling banyak ditemukan di hutan kawatak (tabel 1). Dophla evelina dermoides dan Cepora timnatha merupakan yang paling sedikit ditemukan dengan perolehan masingmasing $0.08 \%$. Hal ini dapat disebabkan oleh kurangnya tanaman inang maupun sumber nektar yang dibutuhkan oleh larva dan kupu-kupu tersebut. Junonia hedonia adalah spesies yang paling banyak ditemukan karena larva bersifat polifag (Lamatoa et al. 2013)

Hutan Danowudu merupakan lokasi penelitian dengan jumlah presentasi yang lebih tinggi dibandingkan dengan hutan lainnya dengan jumlah 497 individu (38.68 \%), diikuti oleh hutan Kawatak yang berjumlah 487 individu (37.90 \%) dan terakhir hutan Masarang dengan 301 individu (23.42 \%). Melimpahnya spesies kupu-kupu di hutan Danowudu dikarenakan hutan tersebut masih alami, memiliki beragam jenis tumbuhan dan tersedianya sumber mata air yang cukup untuk mendukung perkembangan dan pertumbuhan kupu-kupu. Hutan Masarang memiliki lebih sedikit individu karena disebabkan oleh adanya alih fungsi lahan baik di sekitar maupun bagian hutan oleh masyarakat setempat.

Di lokasi hutan Masarang ditemukan spesies Cethosia myrina yang merupakan spesies yang dilindungi berdasarkan UU No 41 Tahun 1999 tentang Kehutanan pasal
50 dan PP Nomor 7 Tahun 1999 yang keberadaannya sangat sedikit di hutan Masarang. Hal ini sesuai pernyataan dari Schulze et al. (2004) bahwa kekayaan spesies endemik dapat berkurang dengan tingginya gangguan dan penggunaan lahan.

Pada ketiga lokasi penelitian ditemukan Cyrestis strigata, Eurema tominia, Idea blanchardii, Ideopsis vitrea vitrea, Junonia hedonia, Melanitis pyrrha Papilio gigon, Papilio sataspes, Parantica cleona luciplena Ini menandakan spesies-spesies ini mampu beradaptasi pada ketiga lingkungan tersebut juga tersedianya beberapa sumber makanan yang sama pada ketiga lokasi hutan tersebut. Hal ini sesuai dengan pernyataan Yustisia (2012) yang menyatakan kupu-kupu merupakan serangga kosmopolitan yang dapat hidup pada berbagai tipe habitat yang berbeda.

Spesies kupu-kupu yang hanya dapat ditemukan di hutan Danowudu dan tidak ditemukan di hutan lainnya yaitu Amathusia phidippus celebensis, Cepora timnatha, Cyrestis cocles, Dophla evelina dermoides, Elodina sota, Elymnias cumaea, Euthalia Amanda, Hebomoia glaucippe celebensis, Lassipa neriphus, Parasarpa lymire, Pareronia tritaea, Tacola eulimene hegelochus dan Troides Helena. Spesies kupu-kupu yang hanya dapat ditemukan di kawatak yaitu Danaus genutia leucoglene, Doleschallia polibete celebensis, Euploea eupator, Nacaduba hermus, Notocrypta clavata, Papilio blumei dan Vindula dejone celebensis. Spesies kupu-kupu yang 
hanya dapat ditemukan di hutan Masarang berjumlah 3 spesies yaitu Cethosia myrina, Hypolimnas salmacis dan Lohora ophthalmica.

Spesies-spesies yang hanya dapat ditemukan di hutan tertentu dapat disebabkan oleh adanya perbedaan jenis vegetasi tumbuhan maupun faktor fisik lainnya seperti suhu, kelembapan dan topografi. Suhu pada ketiga lokasi hutan ini masih pada batas toleransi suhu yang dibutuhkan oleh kupu-kupu. Hutan Danowudu memiliki suhu $29-31{ }^{\circ} \mathrm{C}$, hutan Kawatak dengan suhu $27-29{ }^{\circ} \mathrm{C}$ dan hutan Masarang dengan suhu $25-28{ }^{\circ} \mathrm{C}$. Kisaran suhu yang dibutuhkan oleh kupu-kupu, yaitu suhu minimum $15^{\circ} \mathrm{C}$, suhu optimum $25^{\circ} \mathrm{C}$ dan suhu maksimum $45^{\circ} \mathrm{C}$ (Handayani et al. 2012). Kelembapan yang paling baik terdapat di hutan Danowudu dengan 70-86 \%. Kupu-kupu membutuhkan kelembaban sebesar 84-92 \% untuk berkembang biak (Handayani et al. 2012).

Topografi berpengaruh pada jumlah dari spesies kupu-kupu. Spesies kupu-kupu dapat ditemukan dengan jumlah yang banyak pada ketinggian 400-1000 m dpl (Handayani et al. 2012). Kawatak cocok dengan kriteria ini yaitu memiliki ketinggian 827-938 $\mathrm{m}$ tapi dengan adanya penebangan dan pembukaan lahan menyebabkan kawatak mengalami penurunan spesies kupu-kupu.

Kelimpahan dan kehadiran kupukupu bergantung dari jenis tumbuhan yang terdapat di habitatnya (Putri dan Mutiara 2014). Kelimpahan spesies kupu-kupu yang tertinggi terdapat di hutan Danowudu dengan jumlah 248.5, hutan kawatak dengan 243.5 dan paling sedikit pada hutan Masarang yang berumlah 150.5 (Gambar 2). Kondisi hutan Danowudu yang masih baik membuat kelimpahan kupu-kupu lebih tinggi dibandingkan lokasi hutan lainnya.

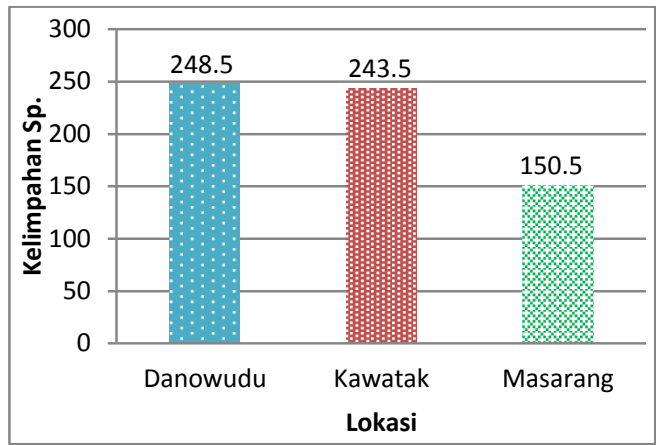

Gambar 2. Kelimpahan spesies kupukupu

Keanekaragaman spesies kupukupu tertinggi yaitu di hutan Danowudu dengan nilai keanekaragaman 2.75, Masarang dengan nilai keanekaragaman yaitu 2.71 dan yang paling sedikit Kawatak dengan nilai keanekaragaman yaitu 2.51 (Gambar 3).

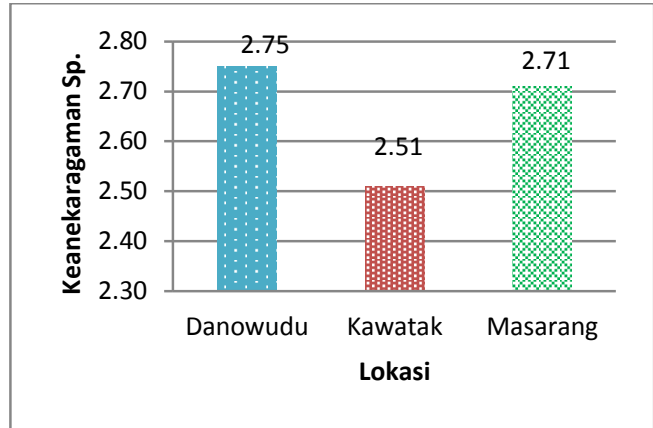

48 JURNAL BIOSLOGOS, AGUSTUS 2016, VOL. 6 N

Keanekaragaman pada ketiga lokasi ini termasuk dalam kategori keanekaragaman sedang. Keanekaragaman sedang dapat disebabkan oleh adanya kelimpahan dan kemerataan yang rendah dilihat dari adanya dominasi beberapa jenis kupukupu. Hutan Danowudu memiliki dominasi kupu-kupu Melanitis pyrrha (91 individu), Parthenos sylvia salentia 
(76 individu), Pareronia tritaea (62 individu). Hutan Kawatak memiliki dominasi kupu-kupu Junonia hedonia (152 individu), Eurema tominia (66 individu) dan hutan Masarang dengan dominasi kupu-kupu Delias zebuda (49 individu).

Kekayaan spesies yang tertinggi terdapat di hutan Danowudu dengan jumlah 30 spesies, diikuti oleh hutan Kawatak dengan jumlah 27 spesies, dan yang paling sedikit yaitu di hutan Masarang dengan 25 spesies (Gambar 4).

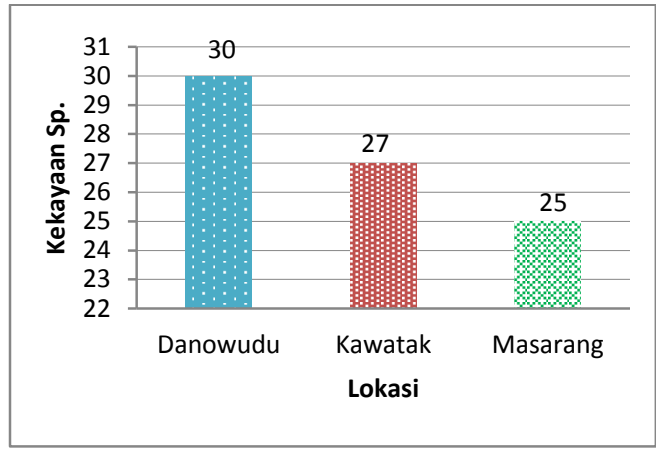

Gambar 4. Kekayaan spesies kupukupu

Tingginya kekayaan spesies di hutan Danowudu karena banyaknya ragam tumbuhan yang menjadi makanan dan tempat bernaung bagi kupu-kupu. Sedangkan pada hutan kawatak dan Masarang terlihat adanya penebangan pohon dan pembukaan lahan pada bagian hutan yang berimbas pada terjadinya penurunan kekayaan spesies di hutan tersebut.

Kemerataan spesies tertinggi terdapat di hutan Masarang dengan nilai 0.84 , kemudian hutan Danowudu dengan nilai 0.81 dan terakhir hutan Kawatak dengan nilai 0.76 (gambar 5).

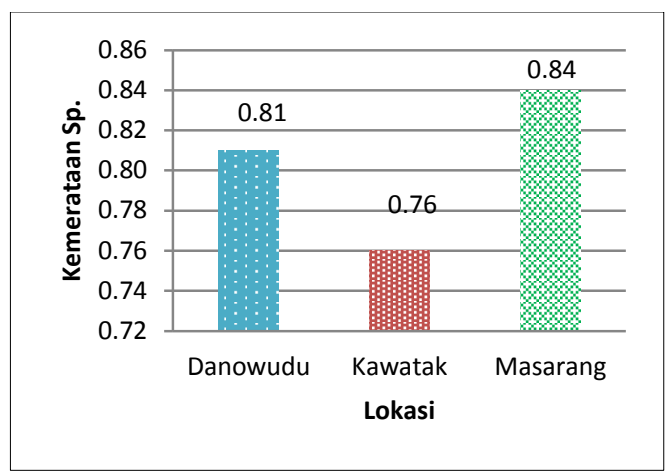

Gambar 5. Kemerataan spesies kupukupu

Kemerataan spesies yang rendah menunjukkan adanya dominasi spesies tertentu pada habitat (Priyono dan Abdullah, 2013). Kawatak memiliki kemerataan spesies terendah karena didominasi oleh spesies Junonia hedonia. Kemerataan spesies tertinggi yang terdapat di hutan Masarang menunjukkan jumlah individu tiap spesies di hutan tersebut hampir sama dan tidak ada yang mendominasi.

\section{KESIMPULAN}

Dari hasil analisis, dapat disimpulkan bahwa kelimpahan dan kekayaan spesies tertinggi di hutan Danowudu (248.5, 30), diikuti oleh hutan Kawatak $(243.5,27)$ dan terendah di hutan Masarang (150.5, 25). Keanekaragaman spesies tertinggi di hutan Danowudu (2.75), diikuti oleh hutan Masarang (2.71) dan terendah di hutan Kawatak (2.51). Kemerataan tertinggi di hutan Masarang (0.84) dan terendah di hutan Kawatak (0.76).

Spesies kupu-kupu yang hanya dapat ditemukan di hutan Danowudu (200-240 mdpl) terdiri dari 13 spesies. Spesies kupu-kupu yang hanya dapat ditemukan di kawatak (827-938 mdpl) terdiri dari 7 spesies. Spesies kupukupu yang hanya dapat ditemukan di 
hutan Masarang (1084-1194 mdpl) terdiri dari 3 spesies.

\section{DAFTAR PUSTAKA}

Bodang Y (2002) Beberapa Aspek Biologi dan Tingkah laku Kupukupu Troides helena hephaestus Felder (Papilionidae) pada Tumbuhan Aristolochia tagala Cham. Tesis. Universitas Sam Ratulangi. Manado.

Chahyadi E dan Bibas E (2016) Jenisjenis Kupu-kupu (Sub Ordo Rhopalocera) yang Terdapat di Kawasan Hapanasan, Kabupaten Rokan Hulu, Provinsi Riau. Jurnal Riau Biologia. 1(8): 50-56

Febrita E, Yustina, Dahmania (2014) Keanekaragaman jenis kupukupu (Subordo Rhopalocera) di Kawasan Wisata Hapanasan Rokan Hulu sebagai Sumber Belajar pada Konsep Keanekaragaman Hayati. Jurnal biogenesis. 10 (2): 48-59 Handayani V, Sugiyanta I, Zulkarnain (2012) Deskripsi Habitat Kupukupu di Taman Kupu-kupu Gita Persada Kelurahan Kedaung Kecamatan Kemiling Kota Bandar Lampung. http://jurnal.fkip.unila.ac.id/ind ex.php/JPG/article/download/6 57/377. (20 Feb-ruari 2016)

Koneri R dan Saroyo (2012) Distribusi dan Keanekaragaman Kupukupu (Lepidoptera) di Gunung Manado Tua, Kawasan Taman Nasional Laut Bunaken, Sulawesi Utara. Jurnal bumi lestari. 12(2) : 357-365

Lamatoa DC, Koneri R, Siahaan R.; Maabuat PV (2013) Populasi Kupu-kupu (Lepidoptera) di Pulau Mantehage, Sulawesi Utara. Jurnal IImiah Sains. 13(1) : 52-56
Lestari DF, Putri RDA, Ridwan M, Purwaningsih AW (2015) Keanekaragaman Kupu-kupu (Insekta: Lepidoptera) di Wana Wisata Alas Bromo, BKPH Lawu Utara, Karanganyar, Jawa Tengah. Pros Sem Nas Masy Biodiv Indon. 1 (6): 1284 12881288

Odum EP (1996) Dasar-Dasar Ekologi. Edisi ke-3. Gadjah Mada University Press. Yogyakarta

Peggie D (2008) Kupu-kupu, Keunikan Tiada Tara. http://www.biologi .lipi.go.id/bio_indonesia/mTem plate.php?h=3\&id_berita=32. (11Februari 2016)

Priyono B dan Abdullah M (2013) Keanekaragaman Jenis Kupukupu di Taman Kehati Unnes. Biosaintifika. 5(2) : 100-105

Putri R dan Mutiara D (2014) Keanekaragaman Kupu-kupu di Kecamatan Sukarame Kota Palembang Provinsi Sumatera Selatan. Sainmatika. 11 (2): 38-4

Rahayu SE dan Basukriadi A (2012) Kelimpahan dan Keanekaragaman Spesies Kupu-kupu (Lepidoptera; Rhopalocera) Pada Berbagai Tipe Habitat di Hutan Kota Muhammad Sabki Kota Jambi. Biospecies, 5 (2) : $40-48$

Schulze $\mathrm{CH}$, Dewenter IS, Tscharntke $T$ (2004) Effects of Land Use on Butterfly Communities at the Rain Forest Margin. Spinger.

50 JURNAL BIOSLOGOS, AGUSTUS 2016, VOL. 6 NC

Yogyakarta

Shalihah A, Pamula G, Cindy R, Rizkawati V, Anwar Zl (2012) Kupu-kupu di kampus Universitas Padjajaran Jatinangor. UNPAD Sumedang 
Syahputra M (2015) Pengukuran Keanekaragaman Kupu-kupu (Lepidoptera dengan menggunakan Metode: Time Search. Media Bina IImiah. 9(4): 68-72
Kebun Botani Upi Bandung. Universitas Pendididikan. Indonesia 